\title{
Typical and atypical antipsychotics differentially affect long-term incidence rates of the metabolic syndrome in first-episode patients with schizophrenia: A retrospective chart review
}

\author{
Marc De Hert ${ }^{\mathrm{a}}$, Vincent Schreurs ${ }^{\mathrm{a}}$, Kim Sweers $^{\mathrm{a}}$, Dominique Van Eyck $^{\mathrm{a}}$, Linda Hanssens ${ }^{\mathrm{b}}$, Sebastjan Šinko ${ }^{\mathrm{c}}$, \\ Martien Wampers ${ }^{\mathrm{a}}$, Andre Scheen ${ }^{\mathrm{d}}$, Joseph Peuskens ${ }^{\mathrm{a}}$, Ruud van Winkel ${ }^{\mathrm{a}, \mathrm{e}}$ \\ ${ }^{a}$ University Psychiatric Center Katholieke Universiteit Leuven, Leuvense Steenweg 517, 3070 Kortenberg, Belgium \\ ${ }^{\mathrm{b}}$ Department of Epidemiology and Public Health, University Liège, Belgium \\ ${ }^{\mathrm{c}}$ Department of psychiatry, University Clinical Center in Maribor, Slovenia \\ ${ }^{\mathrm{d}}$ Department of Diabetes, Nutrition and Metabolic Disorders, CHU Sart Tilman, University Liège, Belgium \\ 'Department of Psychiatry and Neuropsychology, EURON, South Limburg Mental Health Research and Teaching Network, Maastricht \\ University, The Netherlands
}

\begin{abstract}
The presence of the metabolic syndrome (MetS) is an important risk factor for cardiovascular disease and diabetes. There are limited data on the prevalence of MetS in patients with schizophrenia at the onset of the disorder and specifically no data on patients treated in the era when only first-generation antipsychotics were available.
\end{abstract}

Methods: Data from a historic cohort of consecutively admitted first-episode patients with schizophrenia treated with first-generation antipsychotics (FGAs) were compared with an age and sex matched series of consecutive first-episode patients treated only with second-generation antipsychotics (SGAs). Rates of MetS were compared at baseline and after on average 3 years of treatment exposure.

Results: At first episode there was no difference in the prevalence of MetS between the historic and the current cohort. Rates of MetS increased over time in both groups, but patients started on SGAs had a three times higher incidence rate of MetS (Odds Ratio 3.6, CI 1.7-7.5). The average increase in weight and body mass index was twice as high in patients started on SGA. The difference between the FGA and SGA group was no longer significant when patients started on clozapine and olanzapine were excluded.

Conclusion: Rates of MetS at the first episode of schizophrenia today are not different from those of patients 15 to 20 years ago. This finding counters the notion that the high rates of metabolic abnormalities in patients with schizophrenia currently reported are mainly due to lifestyle changes over time in the general population. Some SGAs have a significantly more negative impact on the incidence of MetS compared to FGAs in first-episode patients.

Keywords: schizophrenia ; first episode ; metabolic syndrome ; physical health

\section{Introduction}

In the last decades prevalence rates of obesity have been rising globally (Kautiainen et al., 2002; Ogden et al., 2006; Wang and Beydoun, 2007). This has contributed to increased rates of the metabolic syndrome (MetS) which will impact on physical health in the general population (Byrne and Wild, 2005; Ford et al., 2002, 2004). The metabolic syndrome is a risk factor for diabetes and cardiovascular disease (Byrne and Wild, 2005; Hennekens et al., 2005; Grundy, 2005; Isomaa et al., 2001; Yusuf et al., 2004).

Several studies have shown high prevalence rates of MetS in patients with schizophrenia (Basu et al., 2004; Bobes et al., 2007; Cohn et al., 2004; Correll et al., 2006; De Hert et al., 2006a; Heiskanen et al., 2003; Holt et al., 2004; McEvoy et al., 2005; Meyer et al., 2005; Rejas et al., 2008; Sicras-Mainar et al., 2008; Srisurapanont et al., 2007; Thakore, 2005). Rates of MetS in people with schizophrenia are at least double compared to an age matched population sample (De Hert et al., 2006b). However, most studies were cross-sectional in nature. There are limited data on the evolution over time in patients with schizophrenia, in terms of cohort effects as well as within-person effects.

Metabolic abnormalities have consistently been identified as a part of schizophrenic illness, even before the era of antipsychotic medication (Allison et al., 1999; Homel et al., 2002; Meduna et al., 1942; Raphael, 1921). The interest in this topic has been renewed since the introduction of second-generation antipsychotic s (SGAs) and their possible association with metabolic abnormalities (Allison and Casey, 2001; Henderson, 2005; Newcomer, 2005, 2007a; Scheen and De Hert, 2005, 2007; Tschoner et al., 2007). Next to the impact on physical health these metabolic abnormalities are of major clinical concern, because of their association with a lower functional 
outcome (Lyketsos et al., 2002), a worse perceived physical health (Dixon et al., 1999), poorer quality of life (Awad, 2004; De Hert et al., 2006c) and non-compliance (Weiden et al., 2004).

The reasons that underlie the high prevalence of these metabolic abnormalities are much debated, especially when considering the possible role of SGAs in the occurrence of these abnormalities. Many studies have suggested a role of (certain) SGAs in the occurrence of metabolic abnormalities (Newcomer, 2005). Some studies have provided evidence for an increased prevalence of central obesity and glucose abnormalities such as impaired fasting glucose and insulin resistance in drug-naive first-episode patients, suggesting that metabolic disturbances may even be conceived as intermediary phenotypes associated with genetic risk for schizophrenia (de Leon and Diaz, 2007; Ryan et al., 2003; Spelman et al., 2007; Thakore et al., 2002; Thakore, 2005). Recently a few studies have explored the genetic variations associated with metabolic changes on antipsychotics (de Leon and Diaz, 2007; Ellingrod et al., 2008). Other authors have pointed to the increase in prevalence of metabolic abnormalities in the general population to explain the increase of metabolic abnormalities in schizophrenia (Holt et al., 2004; Holt and Pevelert, 2006).

The current study aimed to compare two different cohorts of patients with schizophrenia admitted for their first episode of psychosis: a historic cohort consisting of subjects who were admitted between 1984 and 1995 and who were treated with first-generation antipsychotics (FGAs), and a current cohort of subjects with similar age and sex distribution who were admitted between 2000 and 2005 and who were treated with SGAs only. To evaluate the potential impact of population changes over time rates of MetS were compared between both groups at baseline before treatment was started. The differential impact of treatment with FGAs compared to SGAs, on the incidence and prevalence of MetS, was evaluated in a subsample of both cohorts on which prospective data over the course of treatment was available. Given the possible impact of SGAs on prevalence rates of metabolic abnormalities in schizophrenia, we hypothesized that rates of MetS would be similar for both cohorts at first admission, and that rates of MetS would increase over time in both groups, but significantly more for the current cohort as a result of treatment with SGAs.

\section{Methods}

Two cohorts of first-episode patients with schizophrenia were compared. Routinely, all patients got a physical examination and a fasting blood assessment when they were admitted to our university psychiatric hospital.

Routine laboratory tests have been performed at our hospital in the same laboratory since the seventies. Assessment of triglycerides became available in 1981 and assessment of HDL cholesterol in 1984.

The historic cohort is derived from a cohort of 1119 patients with schizophrenia consecutively admitted with schizophrenia between 1973 and 1992 (Peuskens et al., 1997; De Hert et al., 2001). All admitted first-episode patients between $1 / 1 / 1984$ and $1 / 1 / 1995$ with complete laboratory data at admission were selected for the study. All patients were treated with high-potency FGAs.

The cohort of current first-episode patients came from an ongoing naturalistic follow-up. The baseline characteristics of included patients and study methods are described in detail elsewhere (De Hert et al., 2006a, b,c; van Winkel et al., 2006). All first-episode patients treated with SGAs with complete data were included.

In both cohorts the follow-up data for the evaluation of MetS over the course of treatment were collected after at least 1 year of treatment exposure. The duration of treatment was matched between the two cohorts.

The presence of the MetS was assessed using the adapted ATP-III criteria (Expert panel, 2001; Grundy et al., 2005 (fasting glucose $\geq 100 \mathrm{mg} / \mathrm{dl}$, plus including treatment for hypertension, - lipidemia and - glycemia as criteria, Tables 1 and 2)). In the historic cohort only weight and BMI were available because measuring waist circumference only became routine in recent years. Following Lean et al. (1995) a schizophrenia specific conversion from BMI to waist was calculated based on a regression analysis on data from 430 patients from the ongoing metabolic study (De Hert et al., 2006a). Waist circumference was predicted according to the following formula: waist $=33.0+(2.4 \times \mathrm{BMI})$ for men and waist $=27.9+(2.4 \times \mathrm{BMI})$ for women.

Differences between cohorts on continuous variables were evaluated by means of one-way ANOVA. To evaluate the evolution over time of continuous variables as function of cohort, a cohort $(2) \times$ time ANOVA was performed. The associations between cohorts and categorical variables were assessed by chi-square tests. The occurrence of MetS in patients without MetS at baseline was predicted based on patient cohort through logistic regression.

The study was approved by the ethical committee of our hospital (University Psychiatric Centre Catholic University Leuven) and all patients from the ongoing metabolic study gave written informed consent. 
Table 1 : Demographics and data at baseline in both cohorts

\begin{tabular}{llll}
\hline & \multicolumn{1}{c}{$\begin{array}{c}\text { Historic cohort } \\
(n=148)\end{array}$} & $\begin{array}{c}\text { Current cohort } \\
(n=148)\end{array}$ & p** \\
\hline Age (years) & $22.3( \pm 3.2)$ & $22.1( \pm 3.1)$ & $\mathrm{ns}$ \\
Weight $(\mathrm{kg})$ & $67.6( \pm 11.9)$ & $69.5( \pm 13.4)$ & $\mathrm{ns}$ \\
BMI $\left(\mathrm{kg} / \mathrm{m}^{2}\right)$ & $22.3( \pm 3.4)$ & $22.5( \pm 3.7)$ & $\mathrm{ns}$ \\
BP systolic $(\mathrm{mmHg})$ & $123( \pm 14)$ & $118( \pm 14)$ & $\mathrm{ns}$ \\
BP diastolic $(\mathrm{mmHg})$ & $79( \pm 10)$ & $72( \pm 11)$ & $\mathrm{ns}$ \\
Pulse (beats/min) & $80( \pm 13)$ & $80( \pm 14)$ & $\mathrm{ns}$ \\
Glucose $(\mathrm{mg} / \mathrm{dl})$ & $89( \pm 15)$ & $84( \pm 7)$ & 0.0055 \\
Cholesterol $(\mathrm{mg} / \mathrm{dl})$ & $182( \pm 37)$ & $172( \pm 35)$ & $\mathrm{ns}$ \\
Triglyceride $(\mathrm{mg} / \mathrm{dl})$ & $100( \pm 56)$ & $110( \pm 72)$ & $\mathrm{ns}$ \\
HDL $(\mathrm{mg} / \mathrm{dl})$ & $53( \pm 16)$ & $55( \pm 23)$ & $\mathrm{ns}$ \\
LDL $(\mathrm{mg} / \mathrm{dl})$ & $103( \pm 35)$ & $98( \pm 33)$ & $\mathrm{ns}$
\end{tabular}

\begin{tabular}{llll} 
& $n(\%)$ & $n(\%)$ & $p^{* *}$ \\
\hline ATP-III A at baseline* & $8(5.4 \%)$ & $7(4.7 \%)$ & $n s$ \\
Waist $(\mathrm{M}>102 \mathrm{~cm}, \mathrm{~F}>88 \mathrm{~cm})$ & $15(10.1 \%)$ & $13(8.8 \%)$ & $\mathrm{ns}$ \\
BP $(\geq 130 / 85 \mathrm{~mm} \mathrm{Hg})$ & $65(43.9 \%)$ & $37(25.0 \%)$ & 0.0006 \\
HDL $(\mathrm{M}<40 \mathrm{mg} / \mathrm{dl}, \mathrm{F}<50 \mathrm{mg} / \mathrm{dl})$ & $33(22.3 \%)$ & $33(22.3 \%)$ & $\mathrm{ns}$ \\
TG $(\geq 150 \mathrm{mg} / \mathrm{dl})$ & $17(11.5 \%)$ & $31(20.9 \%)$ & 0.0273 \\
Glucose $(\geq 100 \mathrm{mg} / \mathrm{dl})$ & $14(9.5 \%)$ & $3(2.0 \%)$ & 0.0060 \\
\hline *
\end{tabular}

*MetS if 3 of 5 criteria are met; **one-way ANOVA; ***Chi-square test.

\section{Results}

\subsection{Patients and rate of MetS at baseline}

Between 1984 and 1995, 301 first-episode patients were admitted to our hospital. A complete laboratory assessment including all the parameters of Mets was available in 148 patients $(49.2 \%)$ before start of medication. There were no significant differences between patients with or without a complete assessment, neither on clinical variables nor on available laboratory results. All patients were started on high-potency FGAs (butyrophenones, diphenylbutylperidines or thioxanthenes).

The matched group of 148 patients treated only with SGAs was prospectively included at first episode between 2000 and 2006.

Both groups $(n=148)$ had similar age at first admission for the first episode $(23.2 \pm 3.4$ versus $22.1 \pm 3.2$ years $)$ and sex distribution (historic sample male $65.5 \%$. versus the current sample male $71.6 \%$ ). In both cohorts more than $95 \%$ were Caucasian and of native Belgian origin.

The prevalence of MetS at first episode before start of treatment was similar in both groups (5.4\%in FGA cohort and $4.7 \%$ in SGA cohort). Elevated blood-pressure and impaired fasting glucose were more frequent in the historic cohort while elevated triglycerides were more frequent in the current cohort. Apart from lower fasting glucose values in the current cohort, there were no significant differences between the groups on baseline metabolic parameters (Table 1).

\subsection{Rates of the metabolic syndrome over time}

Prospective data over the course of treatment were available in a subset of patients in both cohorts. In the historic group an assessment was available on 122 patients $(82.4 \%)$, on average 3.7 years after the start of antipsychotic medication $( \pm 1.4$, min 1 and $\max 7.0$ years $)$. In the current cohort $(n=148), 108$ patients $(73.1 \%)$ had a complete assessment after a mean duration of treatment of 3.2 years $( \pm 1.7$, min 1 and max 6.9 years). The current cohort with complete assessments was younger at first admission $(F=7.72, d f 1,228 p=0.0059)$ and had a shorter duration of follow-up compared to the historic group $(F=5.25, d f 1,28 p=0.0228)$.

In patients with complete MetS assessments (baseline and after an average of 3 years exposure to antipsychotic medication) the rates of MetS were also comparable at baseline assessment, respectively $5.7 \%$ in the historic cohort $(n=122)$ and $5.6 \%$ in the current cohort $(n=108)$, although there were significant differences on individual MetS criteria (Table 2). At baseline there was no difference between the group in weight or BMI. 
During treatment with FGAs $(n=122)$ there were $9.8 \%(n=12)$ new incident cases of MetS resulting in a prevalence of $13.1 \%$. In patients started on SGAs $(n=108)$ there was a more than 2 times higher incidence rate of $27.8 \%(n=30)$ giving rise to a nearly 5 -fold increase in prevalence of $30.6 \%$ compared to baseline (Table 2$)$. The difference in rates after 3 years exposure on FGAs compared to SGAs was highly significant $\left(\mathrm{Chi}^{2}=10.4, d f\right.$ $1, p=0.0013)$.

In patients without MetS at baseline the risk of developing MetS was significantly greater in patients started on SGAs, Odds Ratio 3.6 (FGA as reference, CI 1.7-7.5).

The difference over time was mainly explained by changes over time in glucose and triglycerides (Table 3).

When patients in the SGA group treated with clozapine and olanzapine were excluded from the analysis the difference between the FGA and SGA groups was no longer significant (MetS rate at follow-up FGA 13.1\% and SGA $\left.16.1 \%, \mathrm{Chi}^{2}=0.308, d f 1, p=0.5790\right)$.

Table 2 : -IIIA MetS over time with antipsychotic treatment

\begin{tabular}{llll}
\hline & Baseline & Incidence cases & Follow-up* \\
\hline & $n(\%)$ & $n(\%)$ & $n(\%)$ \\
\hline $\begin{array}{l}\text { Historic cohort on FGA } \\
(n=122)\end{array}$ & $7(5.7 \%)$ & $12(9.8 \%)$ & $16(13.1 \%)$ \\
$\begin{array}{l}\text { Current cohort on SGA } \\
(n=108)\end{array}$ & $6(5.6 \%)$ & $30(27.8 \%)$ & $33(31.6 \%)$
\end{tabular}

$(n=108)$

*A proportion of patients who met MetS criteria at baseline did not meet criteria at follow-up: $2.5 \%$ in the FGA group and $2.8 \%$ in the SGA group respectively

Table 3 : valence of MetS and MetS criteria at baseline and at follow-up in all patients for whom follow-up data were available after on average 3 years

\begin{tabular}{|c|c|c|c|}
\hline & $\begin{array}{l}\text { Historic cohort } \\
(n=122)\end{array}$ & $\begin{array}{l}\text { Current cohort } \\
(n=108)\end{array}$ & $p^{* *}$ \\
\hline & $n(\%)$ & $n(\%)$ & \\
\hline \multicolumn{4}{|l|}{ Baseline } \\
\hline ATP-III A at baseline* & $7(5.7 \%)$ & $6(5.6 \%)$ & ns \\
\hline Waist $(\mathrm{M}>102 \mathrm{~cm}, \mathrm{~F}>88 \mathrm{~cm})$ & $12(9.8 \%)$ & $12(11.1 \%)$ & ns \\
\hline $\mathrm{BP}(\geq 130 / 85 \mathrm{~mm} \mathrm{Hg})$ & $52(42.6 \%)$ & $28(25.9 \%)$ & 0.0080 \\
\hline HDL $(\mathrm{M}<40 \mathrm{mg} / \mathrm{dl}, \mathrm{F}<50 \mathrm{mg} / \mathrm{dl})$ & $28(22.9 \%)$ & $25(23.1 \%)$ & ns \\
\hline $\mathrm{TG}(\geq 150 \mathrm{mg} / \mathrm{dl})$ & $13(10.7 \%)$ & $25(23.1 \%)$ & 0.0109 \\
\hline Glucose $(\geq 100 \mathrm{mg} / \mathrm{dl})$ & $11(9.0 \%)$ & $3(2.8 \%)(3)$ & 0.0483 \\
\hline \multicolumn{4}{|l|}{ Follow-up } \\
\hline ATP-III A at follow-up* & $16(13.1 \%)$ & $33(30.6 \%)$ & 0.0013 \\
\hline Waist $(M \geq 94 \mathrm{~cm}, F \geq 80 \mathrm{~cm})$ & $25(20.5 \%)$ & $33(30.6 \%)$ & ns \\
\hline $\mathrm{BP}(\geq 130 / 85 \mathrm{~mm} \mathrm{Hg})^{* *}$ & $41(33.6 \%)$ & $45(41.7 \%)$ & ns \\
\hline $\operatorname{HDL}(\mathrm{M}<40 \mathrm{mg} / \mathrm{dl}, \mathrm{F}<50 \mathrm{mg} / \mathrm{dl})$ & $36(29.5 \%)$ & $41(38.0 \%)$ & ns \\
\hline $\mathrm{TG}(\geq 150 \mathrm{mg} / \mathrm{dl})$ & $35(28.7 \%)$ & $55(50.9 \%)$ & 0.0006 \\
\hline Glucose $(\geq 100 \mathrm{mg} / \mathrm{dl})$ & $8(6.6 \%)$ & $16(14.8 \%)$ & 0.0409 \\
\hline
\end{tabular}

*MetS if 3 of 5 criteria are met; ${ }^{* *}$ Chi-square test.

\subsection{Changes in individual metabolic parameters}

Significant weight changes over time occurred in both groups. Patients treated with FGAs gained $5.2 \mathrm{~kg}( \pm 9.1$ $\mathrm{kg}$, $\min -12.0 \mathrm{~kg}$, $\max 38.0 \mathrm{~kg})$ on average, while people started on SGAs gained $11.5 \mathrm{~kg}( \pm 11.3 \mathrm{~kg}, \min -12.2$ $\mathrm{kg}$, $\max 56.7 \mathrm{~kg})$. The difference in weight gain between the 2 cohorts was highly significant $(F=22.1, d f 1,228$ $p<0.0001$ ), as well as the proportion of patients experiencing a $>7 \%$ change in weight form baseline (FGA $36.9 \%$ versus $\left.\mathrm{SGA} 72.2 \%, \mathrm{Chi}^{2}=28.7, \mathrm{df} 1, \mathrm{p}<0.0001\right)$.

The changes in weight resulted in significant changes in BMI over time and differences between the groups at follow-up (Table 3 ). In both groups there was a significant increase of overweight and obesity over time (FGA $\mathrm{Chi}^{2}=54.2$, df $1, p<0.0001 ; \mathrm{SGA} \mathrm{Chi}^{2}=31.2$, df 1, p<0.0001). The difference at follow-up between the 2 cohorts was significant $\left(\mathrm{Chi}^{2}=14.2, d f 2, p=0.0008\right)$. 
In both groups levels of HDL and triglycerides deteriorated significantly over time, the increase in triglycerides was significantly larger in patients on SGAs. For all laboratory metabolic parameters there was an effect of time and there were significant group $\times$ time interactions for glucose, total cholesterol and HDL cholesterol (Table 4).

At 3 years follow-up impaired fasting glucose was more frequent in patients treated with SGAs $(\mathrm{Chi}=4.2, d f 1$, $p=0.0409$ ). In both groups 2 patients developed diabetes. In the current cohort 2 patients were started on oral antidiabetic medication for sustained prediabetic abnormalities.

There was no effect of age of first admission on any of the metabolic outcome measures.

\subsection{Effects of individual antipsychotic agents in the SGA cohort}

Of the patients started on SGAs 54.6\% were still on the same antipsychotic at follow-up (mean duration of exposure 2.8 years \pm 0.9 ). On average $2.6 \pm 0.9$ medication switches occurred during the 3 year follow-up. The mean duration of exposure to the SGAs the patients received at follow-up was 2.1 years $( \pm 1.4)$.

In the SGA group at 3 years follow-up the occurrence of MetS depends on which SGA the patients were on, MetS was significantly more prevalent in patients both treated with clozapine $(58.3 \%)$ or olanzapine $(47.1 \%)$ and least prevalent in patients on aripiprazole $(10 \%)\left(\mathrm{Chi}^{2}=15.3, d f 5, p=0.0092\right)$ (Table 5).

Table 4 : Evolution of metabolic parameters over time in both cohorts in patients for whom follow-up data were available after on average 3 years

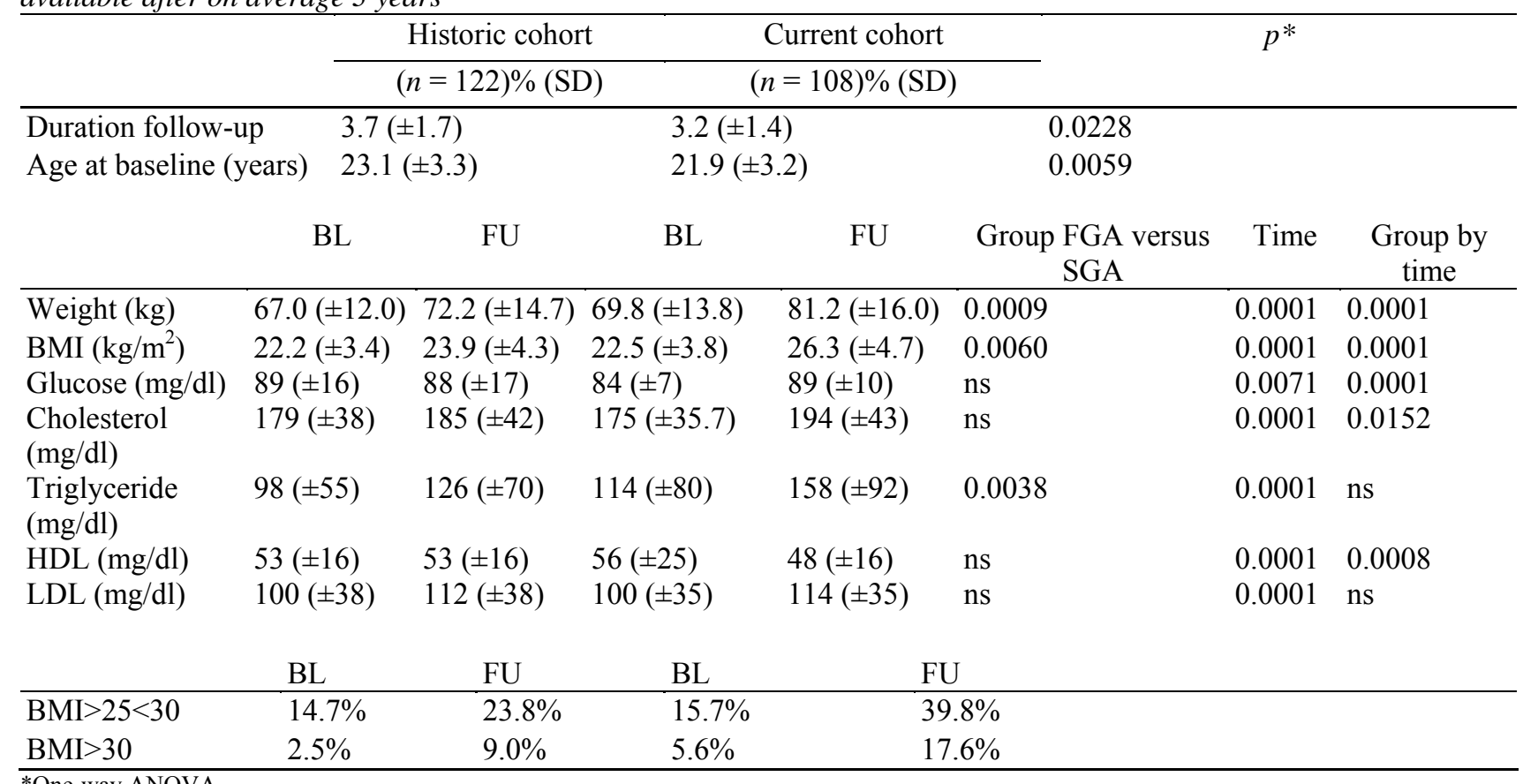

*One-way ANOVA.

Table 5 : ATP-IIIA MetS per antipsychotic in the SGA group

\begin{tabular}{lll}
\hline & Baseline & Follow-up \\
\cline { 2 - 3 } & $n(\%)$ & $n(\%)$ \\
\hline Amisulpride $(n=8)$ & $1(12.5 \%)$ & $2(25 \%)$ \\
Aripiprazole $(n=10)$ & $1(10.0 \%)$ & $1(10.0 \%)$ \\
Clozapine $(n=12)$ & $1(8.3 \%)$ & $7(58.3 \%)$ \\
Olanzapine $(n=34)$ & $1(5.8 \%)$ & $16(47.1 \%)$ \\
Risperidone $(n=24)$ & $1(4.1 \%)$ & $4(16.7 \%)$ \\
Quetiapine $(n=20)$ & $1(4.8 \%)$ & $3(15.0 \%)$ \\
\hline
\end{tabular}




\subsection{Long-term outcomes in the historic cohort}

During the follow-up of on average 3 years 15 patients of the historic cohort (5\%) had died, 13 of which were suicides $(4.3 \%)$ and 2 were cardiovascular deaths $(0.7 \%)$, compared to no deaths in the current cohort. The difference in both suicide and mortality rate was significant (suicide Chi $=6.6, d f 1, p=0.0063$, mortality $\mathrm{Chi}^{2}=$ 7.6, $d f 1, p=0.0036)$.

On 130 patients of the historic cohort (43.2\%) clinical and mortality data were available up to date (mean duration of follow-up $17.2( \pm 2.7)$ years). Of this group 6 , more patients had died (5 suicides and 1 cancer death) and another 8 patients had developed diabetes (6.1\%). Two while still on a FGA and 6 when they were treated on SGA later in the course of the illness (4 on clozapine, of which 2 with ketoacidosis; 1 on olanzapine and 1 on risperidone).

\section{Discussion}

To our knowledge this is the first study evaluating baseline and prospective MetS data in first-episode patients comparing treatment with FGAs and SGAs.

There were no significant difference in rates of MetS at the first episode between patients admitted to hospital today and patients admitted 15 to 20 years ago in the sample under study, although there were significant differences in rates on individual MetS criteria. This suggests that possible population lifestyle changes do not play an important role before treatment is started.

At baseline patients in both groups had similar weight and BMI. Over an average duration of treatment of 3 years there was a significant increase in weight and BMI in both groups. But the group started on SGAs experienced more significant weight gain, $11.8 \mathrm{~kg}$ on average. This dramatic weight gain in young people might well counterbalance the impact on compliance gained by inducing less extrapyramidal side-effects and will impact on quality of life (Awad, 2004; De Hert et al., 2006c; Weiden et al., 2004).

The changes in weight were accompanied by increasing rates of MetS over the course of treatment. Rates doubled in patients started on FGAs but there was a 5 fold increase in patients started on SGAs. After 3 years of exposure of SGAs nearly 1 out of 3 first-episode patients met criteria of MetS. Most of the difference in rates of MetS between FGAs and SGAs was explained by weight gain and changes in triglycerides and fasting glucose levels.

The odds of developing MetS in MetS naive patients were 3-fold in patients started on SGAs compared to FGAs, and there were significant differences between SGAs in their risk to induce MetS in first-episode patients. The differences observed between the FGA and SGA groups were mainly explained with the metabolically deleterious effects of clozapine and olanzapine.

Our data on metabolic changes were in alignment with recent prospective studies in first-episode patents (Attux et al., 2007; Perez-Iglesias et al., 2008; Saddichha et al., 2007; Srisurapanont et al., 2007) and confirmed the differences between SGA in their liability to induce metabolic changes (Cohn and Sernyak, 2006; L'Italien et al., 2007; Newcomer, 2005; van Winkel et al., 2008).

MetS is a know risk factor for type-2 diabetes and cardiovascular disease (Byrne and Wild, 2005; Grundy 2005; Isomaa et al., 2001; Yusuf et al., 2004). The high rates of MetS in patients with schizophrenia and specifically patients treated with SGA should be a concern to clinicians because of the trend of still increasing premature mortality due to cardiovascular illness in people with schizophrenia while the risk for cardiovascular mortality in the general population continues to go down (Brown et al., 2000; Capasso et al., 2008; Hennekens et al., 2005, Joukamaa et al., 2001; Osby et al., 2000a,b; Osby, 2007).

The long-term observation of patients from the historic cohort confirms the high rate of premature mortality, mainly due to suicide early in the course of the disorder. Although confirmation by other studies is needed the significant difference in suicide rates between first-episode patients treated with FGA and SGA is a clinically relevant finding that should be considered in the ongoing post CATIE debate on differences in clinical effectiveness of antipsychotics and metabolic side-effects.

Limitations of the study are that the data were collected at only one site which might impact on generalisability of the results. We did not collect the exact drugs, switches over time between agents nor eventual polypharmacy in patients from the historic cohort. Although laboratory tests were performed in the same laboratory, techniques have changed over time, which may partly explain some of the differences found in individual laboratory results. Because we did not have waist measurements in the historic cohort we have used a conservative conversion factor. This factor was based on previous data obtained in a cross-sectional study in patients with schizophrenia (De Hert et al., 2006a). In both groups patients were prescribed medication but there was no way to control for actual compliance with medication. Both groups had a similar ethnic background and BMI at baseline but we 
have no evaluation on family history of metabolic abnormalities nor measurements of fasting insulin in the historic cohort. Potential awareness and screening bias might have influenced the results because today patients are more closely monitored for potential metabolic side-effects. Lastly both age at first admission and length of follow-up significantly differed between groups with complete assessment both at baseline and follow-up. But the younger age and the shorter duration of follow-up in the current cohort would only potentially have favoured the SGA group. Given these possible sources of bias, the current results need to be interpreted with caution. Nevertheless, the results seem in line with existing literature suggesting a greater impact of SGAs on metabolic parameters, with the greatest impact for clozapine and olanzapine.

To conclude, first-episode patients with schizophrenia are at high risk to develop MetS early in the course of the disorder. The risk is significantly higher in patients started on SGAs. In line with published guidelines our results support the need for close monitoring of metabolic abnormalities and preferential use of metabolic neutral agents in this population as first line treatment option (Cohn and Sernyak, 2006; De Hert et al., 2006d; De Nayer et al., 2005; Marder et al., 2004; Newcomer, 2005, 2007a,b).

\section{Role of funding source}

None.

\section{Contributors}

Study design: M De Hert, R van Winkel.

Data collection: M De Hert, V Schreurs, K Sweers, S Šinko, D Van Eyck.

Statistics: M Wampers.

Writing manuscript: M De Hert wrote the first draft of the manuscript. V Schreurs, K Sweers, S Šinko, D Van Eyck, L Hanssens, M Wampers, R van Winkel, A Scheen and J Peuskens commented on this first draft and contributed to the subsequent revision.

\section{Conflict of interest}

None.

\section{Acknowledgements}

None.

\section{References}

Allison, D.B., Casey, D.E., 2001. Antipsychotic-induced weight gain: a review of the literature. J. Clin. Psychiatry 62 (Suppl 7), $22-31$.

Allison, D.B., Fontaine, K.R., Heo, M., Mentore, J.L., Cappelleri, J.C., Chandler, L.P., Weiden, P.J., Cheskin, L.J., 1999. The distribution of body mass index among individuals with and without schizophrenia. J. Clin. Psychiatry 60 (4), 215-220.

Attux, C, Quintana, M.I., Chaves, A.C., 2007. Weight gain, dyslipidemia and altered parameters for metabolic syndrome on first episode psychotic patients after six-month follow-up. Rev. Bras. Psiquiatr. 29 (4), 346-349.

Awad, G.A., 2004. Antipsychotic medications: compliance and attitudes towards treatment. Curr. Opin. Psychiatry 17, 75-80.

Basu, R., Brar, J.S., Chengappa, K.N., John, V, Parepally, H, Gershon, S., Schlicht, P., Kupfer, D.J., 2004. The prevalence of the metabolic syndrome in patients with schizoaffective disorder-bipolar subtype. Bipolar Disord. 6 (4), 314-318.

Bobes, J., Arango, C., Aranda, P., Carmena, R., Garcia-Garcia, M., Rejas, J., 2007. Cardiovascular and metabolic risk in outpatients with schizophrenia treated with antipsychotics: results of the CLAMORS Study. Schizophr. Res. 90 (1-3), 162-173.

Brown, S., Inskip, H., Barraclough, B., 2000. Causes of the excess mortality of schizophrenia. Br. J. Psychiatry 177, $212-217$.

Byrne, C.D., Wild, S.H., 2005. The global burden of the metabolic syndrome and its consequences for diabetes and cardiovascular disease. In: Byrne, C.D., Wild, S.H. (Eds.), The Metabolic Syndrome. John Wiley \& Sons, West Sussex, Md, pp. 1-42.

Capasso, R.M., Lineberry, T.W., Bostwick, J.M., Decker, P.A., St Sauver, J., 2008. Mortality in schizophrenia and schizoaffective disorder: an Olmsted County, Minnesota cohort: 1950-2005. Schizophr. Res. 98 (1-3), 287-294.

Cohn, T.A., Sernyak, M. J., 2006. Metabolic monitoring for patients treated with antipsychotic medications. Can. J. Psychiatry 51,492-501.

Cohn, T., Prud'homme, D., Streiner, D., Kameh, H., Remington, G., 2004. Characterizing coronary heart disease risk in chronic schizophrenia: high prevalence of the metabolic syndrome. Can. J. Psychiatry 49 (11), 753-760.

Correll, C.U., Frederickson, A.M., Kane, J.M., Manu, P., 2006. Metabolic syndrome and the risk of coronary heart disease in 367 patients treated with second-generation antipsychotic drugs. J. Clin. Psychiatry 67 (4), 575-583.

De Hert, M., McKenzie, K., Peuskens, J., 2001. Risk factors for suicide in young patients suffering from schizophrenia. Schizophr. Res. 47, $127-134$ 
De Hert, M., van Winkel, R., Van Eyck, D., Hanssens, L., Wampers, M., Scheen, A., Peuskens, J., 2006a. Prevalence of the metabolic syndrome in patients with schizophrenia treated with antipsychotic medication. Schizophr. Res. 83 (1), 87-93.

De Hert, M., van Winkel, R., Van Eyck, D., Hanssens, L., Wampers, M., Scheen, A., Peuskens, J., 2006b. Prevalence of diabetes, metabolic syndrome and metabolic abnormalities in schizophrenia over the course of the illness: a cross-sectional study. Clin. Pract. Epidemiol. Ment. Health (2:14 online). doi:10.1186/1745-0179-2-14.

De Hert, M., Peuskens, B., van Winkel, R., Kalnicka, D., Hanssens, L., Van Eyck, D., Wyckaert, S., Peuskens, J., 2006c. Body weight and self-esteem in patients with schizophrenia evaluated with B-WISE®. Schizophr. Res. 88, 222-226.

De Hert, M., Van Eyck, D., De Nayer, A., 2006d. Metabolic abnormalities associated with second generation antipsychotics: fact or fiction? Development of guidelines for screening and monitoring. Int. Clin. Psychopharmacol. 21 (Suppl 2), 11-15.

de Leon, J., Diaz, F. J., 2007. Planning for the optimal design of studies to personalize antipsychotic prescriptions in the post-CATIE era: the clinical and pharmacoepidemiological data suggest that pursuing the pharmacogenetics of metabolic syndrome complications (hypertension, diabetes mellitus and hyperlipidemia) may be a reasonable strategy. Schizophr. Res. 96 (1-3), 185-197.

De Nayer, A., De Hert, M., Scheen, A., Van Gaal, L., Peuskens, J., 2005. Conference report: Belgian consensus on metabolic problems associated with second-generation antipsychotics. Int. J. Psychiatry Clin. Pract. 9 (2), 130-137.

Dixon, L., Postrado, L., Delahanty, J., Fischer, P.J., Lehman, A., 1999. The association of medical comorbidity in schizophrenia with poor physical and mental health. J. Nerv. Ment. Dis. 187 (8), 496-502.

Ellingrod, V.L., Miller, D.D., Taylor, S.F., Moline, J., Holman, T., Kerr, J., 2008. Metabolic syndrome and insulin resistance in schizophrenia patients receiving antipsychotics genotyped for the methylenetetrahydrofolate reductase (MTHFR) 677C/T and 1298A/C variants. Schizophr. Res. 98 (1-3), 47-54.

Expert Panel on Detection and Evaluation of Treatment of High Blood Cholesterol in Adults, 2001. Executive summary of the third report of the National Cholesterol Education Program (NCEP) expert panel on detection, evaluation and treatment of high blood cholesterol in adults (Adult Treatment Panel III). JAMA 285, 2486-2497.

Ford, E.S., Giles, W.H., Dietz, W.H., 2002. Prevalence of the metabolic syndrome among US adults: findings from the third National Health and Nutrition Examination Survey. JAMA 287 (3), 356-359.

Ford, E.S., Giles, W.H., Mokdad, A.H., 2004. Increasing prevalence of the metabolic syndrome among US. Adults Diabetes Care 27 (10), $2444-2449$

Grundy, S.M., 2005. The changing face of cardiovascular risk. JACC 46, 173-176.

Grundy, S.M., Cleeman, J.I., Daniels, S.R., Donate, K.A., Eckel, R.H., Franklin, B.A., Gordon, D.J., Krauss, R.M., Savage, P.J., Smith, S.C., Spertus, J.A., Costa, R., 2005. Diagnosis and management of the metabolic syndrome: an American Heart Association/National Heart, Lung, and Blood Institute Scientific Statement. Circulation 112, 2735-2752.

Heiskanen, T., Niskanen, L., Lyytikainen, R., Saarinen, P.I., Hintikka, J., 2003. Metabolic syndrome in patients with schizophrenia. J. Clin. Psychiatry 64 (5), 575-579.

Hennekens, C.H., Hennekens, A.R., Hollar, D., Casey, D.E., 2005. Schizophrenia and increased risks of cardiovascular disease. Am. Heart J. $150(6), 1115-1121$

Homel, P., Casey, D., Allison, D.B., 2002. Changes in body mass index for individuals with and without schizophrenia, 1987-1996. Schizophr. Res. 55 (3), 277-284.

Henderson, D.C., 2005. Schizophenia and comorbid metabolic disorders. J. Clin. Psychiatry 66 (6, suppl), 11-20.

Holt, R.I.G., Pevelert, R.C., 2006. Antipsychotic drugs and diabetes — an application of the Austin Bradford Hill criteria. Diabetologia 49, $1467-1473$.

Holt, R.I.G., Pevelert, R.C., Byrne, C.D., 2004. Schizophrenia, the metabolic syndrome and diabetes. Diabet. Med. $21,515-523$.

Isomaa, B., Almgren, P., Tuomi, T., Forsen, B., Lahti, K., Nissen, M., Taskinen, M.R., Groop, L., 2001. Cardiovascular morbidity and mortality associated with the metabolic syndrome. Diabetes Care 24 (4), 683-689.

Joukamaa, M., Heliovaara, M., Knekt, P., 2001. Mental disorders and cause-specific mortality. Br. J. Psychiatry 179, 498-502.

Kautiainen, S., Rimpela, A.H., Vikat, A., Virtanen, S.M., 2002. Secular trends in overweight and obesity among Finnish adolescents in 19771999. Int. J. Obes. Relat. Metab. Disord. 26 (4), 544-552.

Lean, M.E., Han, T.S., Morrison, C.E., 1995. Waist circumference as a measure for indicating need for weight management. BMJ 311 (6998), 158-161.

L'Italien, G.J., Casey, D.E., Kan, H.J., Carson, W.H., Marcus, R.N., 2007. Comparison of metabolic syndrome incidence among schizophrenia patients treated with aripiprazole versus olanzapine or placebo. J. Clin. Psychiatry 68 (10), 1510-1516.

Lyketsos, C.G, Dunn, G, Kaminsky, M.J., Breakey, W.R., 2002. Medical comorbidity in psychiatric inpatients: relation to clinical outcomes and hospital length of stay. Psychosomatics 43 (1), 24-30.

Marder, S.R., Essock, S.M., Miller, A.L., Buchanan, R.W., Casey, D.E., Davis, J.M., Kane, J.M., Lieberman, J.A., Schooler, N.R., Covell, N., Stroup, S., Weissman, E.M., Wirshing, D.A., Hall, C.S., Pogach, L., Pi-Sunyer, X., Bigger, J.T., Friedman, A., Kleinberg, D., Yevich, S.J., Davis, B., Shon, S., 2004. Physical health monitoring of patients with schizophrenia. Am. J. Psychiatry 161 (8), 1334-1349.

McEvoy, J.P., Meyer, J.M., Goff, D.C., Nasrallah, H.A., Davis, S.M., Sullivan, L., Meltzer, H.Y., Hsiao, J., Scott Stroup, T., Lieberman, J.A., 2005. Prevalence of the metabolic syndrome in patients with schizophrenia: baseline results from the Clinical Antipsychotic Trials of Intervention Effectiveness (CATIE) schizophrenia trial and comparison with national estimates from NHANES III. Schizophr. Res. 80 (1), $19-32$. 
Published in: Schizophrenia Research (2008), vol. 101, iss. 1-3, pp. 295-303.

Status: Postprint (Author's version)

Meduna, L., Gerty, F., Urse, V., 1942. Biochemical disturbances in mental disorders. Arch. Neurol. Psychiatry 47, $38-52$.

Meyer, J.M., Nasrallah, H.A., McEvoy, J.P., Goff, D.C., Davis, S.M., Charkos, M., Pakel, J.K., Keefe, R.S., Stroup, T.S., Lieberman, J.A., 2005. The Clinical Antipsychotic Trials of Intervention Effectiveness (CATIE) Schizophrenia Trial: clinical comparison of subgroups with and without the metabolic syndrome. Schizophr. Res. 80, 9-18.

Newcomer, J.W., 2005. Second-generation (atypical) antipsychotics and metabolic effects: a comprehensive literature review. CNS Drugs 19 (Suppl 1), 1-93.

Newcomer, J.W., 2007a. Antipsychotic medications: metabolic and cardiovascular risk. J. Clin. Psychiatry 68 (Suppl 4), 8-13.

Newcomer, J., 2007b. Metabolic syndrome and mental illness. Am. J. Manag. Care 13, 170-177.

Perez-Iglesias, R., Crespo-Facorro, B., Martinez-Garcia, O., Ramirez-Bonilla, MX., Alvarez-Jimenez, M., Pelayo-Teran, J.M., GarciaUnzueta, M.T., Amado, J.A., Vazquez-Barquero, J.L., 2008. Weight gain induced by haloperidol, risperidone and olanzapine after 1 year: findings of a randomized clinical trial in a drug-naïve population. Schizophr. Res. doi:10.1016/j.schres.2007.10.022 (Available online 3 December 2007).

Ogden, C.L., Carroll, M.D., Curtin, L.R., McDowell, M.A., Tabak, C.J., Flegal, K.M., 2006. Prevalence of overweight and obesity in the United States, 1999-2004. JAMA 295, 1549-1555.

Osby, U., 2007. Continued increase in cardiovascular mortality in patients with schizophrenia in Sweden, trends over time till 2005. Personal communication.

Osby, U., Correia, N., Brandt, L., Ekbom, A., Sparen, P., 2000a. Mortality and causes of death in schizophrenia in Stockholm county, Sweden. Schizophr. Res. 45 (1-2), 21-28.

Osby, U., Correia, N, Brandt, L., Ekbom, A., Sparen, P., 2000b. Time trends in schizophrenia mortality in Stockholm county, Sweden: cohort study. BMJ 321 (7259), 483-484.

Peuskens, J., De Hert, M., Cosyns, P., Pieters, G, Theys, P., Vermote, R., 1997. Suicide in young schizophrenic patients during and after inpatient treatment. Int. J. Ment. Health 25 (4), 39-44.

Raphael, T.P., 1921. Blood sugar studies in dementia praecox and manic depressive insanity. Arch. Neurol. Psychiatry 5, 687-709.

Rejas, J., Bobes, J., Arango, C, Aranda, P., Carmena, R., Garcia-Garcia, M., 2008. Concordance of standard and modified NCEP ATP III criteria for identification of metabolic syndrome in outpatients with schizophrenia treated with antipsychotics: a corollary from the CLAMORS study. Schizophr. Res. doi:10.1016/j.schres.2007.10.015 (Available online 11 December 2007).

Ryan, M.C., Collins, P., Thakore, J.H., 2003. Impaired fasting glucose tolerance in first-episode, drug-naive patients with schizophrenia. Am. J. Psychiatry $160(2), 284-289$.

Saddichha, S., Ameen, S., Akhtar, S., 2007. Incidence of new onset metabolic syndrome with atypical antipsychotics in first episode schizophrenia: a six-week prospective study in Indian female patients. Schizophr. Res. 95 (1-3), 247.

Scheen, A.J., De Hert, M., 2005. Drug-induced diabetes mellitus: the example of atypical antipsychotics. Rev. Med. Liege 60 (5-6), 455-460. Scheen, A., De Hert, M., 2007. Abnormal glucose metabolism in patients treated with antipsychotics. Diabetes Metab. 33, 169-175.

Sicras-Mainar, A., Blanca-Tamayo, M., Rejas-Gutiérrez, J., Navarro-Artieda, R., 2008. Metabolic syndrome in outpatients receiving antipsychotic therapy in routine clinical practice: a cross-sectional assessment of a primary health care database. Eur. Psychiatr. doi:10.1016/j.eurpsy.2007.07.005 (Available online 29 September 2007)

Spelman, L.M., Walsh, P.L., Sharifi, N, Collins, P., Thakore, J.H., 2007. Impaired glucose tolerance in first-episode drug-naive patients with schizophrenia. Diabet. Med. 24 (5), 481-485.

Srisuxapanont, M., Likhitsathian, S., Boonyanaruthee, V, Charnsilp, C, Jarusuraisin, N., 2007. Metabolic syndrome in Thai schizophrenic patients: a naturalistic one-year follow-up study. BMC Psychiatry 23(4), 7:14.

Thakore, J.H., 2005. Metabolic syndrome and schizophrenia. Br. J. Psychiatry 186, 455-456

Thakore, J.H., Mann, J.N., Vlahos, I., Martin, A., Reznek, R., 2002. Increased visceral fat distribution in drug-naive and drug-free patients with schizophrenia. Int. J. Obes. Relat. Metab. Disord. 26 (1), 137-141.

Tschoner, A., Engl, J., Laimer, M., Kaser, S., Rettenbacher, M., Fleischhacker, W., Patsch, J., Ebenbichler, C, 2007. Metabolic side effects of antipsychotic medication. Int. J. Clin. Pract. 61 (8), 1356-1370.

van Winkel, R., De Hert, M., Van Eyck, D., Hanssens, L., Wampers, M., Scheen, A., Peuskens, J., 2006. Screening for diabetes and other metabolic abnormalities in patients with schizophrenia: evaluation of incidence and screening methods. J. Clin. Psychiatry 67 (10), 14931500 .

van Winkel, R., De Hert, M., Wampers, M., Van Eyck, D., Hanssens, L., Scheen, A., Peuskens, J., 2008. Major changes in glucose metabolism including new-onset diabetes within 3 months after initiation or switch of atypical antipsychotic medication in patients with schizophrenia and schizoaffective disorder. J Clin Psychiatry. el-e8 (pii: ej07m03557).

Wang, Y., Beydoun, M.A., 2007. The obesity epidemic in the United States-gender, age, socioeconomic, racial/ethnic, and geographic characteristics: a systematic review and meta-regression analysis. Epidemiol. Rev. 29, 6-29.

Weiden, P.J., Mackell, J.A., McDonnell, D.D., 2004. Obesity as a risk factor for antipsychotic noncompliance. Schizophr. Res. 66 (1), $51-57$.

Yusuf, S., Hawken, S., Ounpuu, S., Dans, T., Avezum, A., Lanas, F., McQueen, M., Budaj, A., Pais, P., Varigos, J., Lisheng, L.,

INTERHEART Study Investigators, 2004. Effect of potentially modifiable risk factors associated with myocardial infarction in 52 countries (the INTERHEART study): case-control study. Lancet 364 (9438), 937-952. 